\title{
CULTURA ESCRITA Y JUSTICIA PENAL. EL DISCURSO SOBRE LAS PENAS Y OTROS LIBROS DE SU ÉPOCA ${ }^{1}$
}

\author{
Ana Carolina Ibarra \\ Universidad Nacional Autónoma de México
}

Of all the worlds created by man, the world of books is the most powerful.

Heinrich Heine

n la bibliografía del siglo xvirI existe un grupo de libros
que circuló con bastante amplitud. Se trata de traba-
jos que se refieren al tema de las cárceles, las prisiones y los
castigos, temas que quizá hoy en día no pensaríamos que
pudieran ser de interés general. Sin embargo, estos escri-
tos lo fueron. Una parte de ello se explica por el hecho de
que la prisión no era una posibilidad tan lejana para la gente
de la época, ni tampoco lo eran los castigos tremendos que
en general se llevaban a cabo a la vista de todos en las pla-
zas públicas, convirtiéndose en espectáculo y escarmiento
al mismo tiempo. Al estudiar algunas publicaciones de la Fecha de recepción: 3 de febrero de 2015 Fecha de aceptación: 27 de mayo de 2015

${ }_{1}$ Agradezco el apoyo de Eva Guadalupe Hernández. 
época que se centran en temas de justicia penal y su circulación, es posible conocer cuáles eran aquellos aspectos del Antiguo Régimen que se habían puesto en cuestión, tales como los alcances de la justicia real, la excesiva crueldad de los tormentos y la posibilidad de redimir a los delincuentes. Para entender el curso de algunas de estas ideas en el mundo americano, vale la pena estudiar dos grandes obras que circularon en aquella época: el gran libro del Marqués de Beccaria sobre los delitos y las penas, cuya primera edición salió en 1764, y el Discurso sobre las penas del jurista americano Lardizábal, de 1782. Si uno reconstruye su historia puede entender un poco mejor cómo fue que los escritos constitucionales que se sancionaron décadas más tarde caían en un terreno abonado previamente por estas nuevas ideas.

Aunque muchos de estos escritos no llegaron de manera directa a manos de la gente (algunos fueron prohibidos y otros llegaban sólo a un público selecto), sus inquietudes impregnaron el ambiente y, por medio de obras más populares, piezas de teatro o folletos, empezaron a difundirse en muchos lugares. ${ }^{2}$ Desde luego, es imposible dar cuenta cabal de la recepción de estas publicaciones, sin embargo, vale la pena insistir en que en el periodo de la independencia muchas de sus propuestas se habían filtrado a las esferas

2 Por ejemplo, en 1773, Gaspar Melchor de Jovellanos escribió El delincuente honrado, una pieza teatral que cuestiona el empleo de la tortura en los tribunales y sistemas de justicia en la Monarquía española a propósito de los duelos a muerte. En algunas de sus páginas puede leerse un elegante cuestionamiento a los suplicios: "La tortura. ¡ $\mathrm{Oh}$, nombre odioso! ¡Nombre funesto! ¿Es posible que en un siglo en el que se respeta la humanidad y en que la filosofía derrama su luz por todas partes, se escuchen aún entre nosotros los gritos de la inocencia oprimida?”. 
cultas del virreinato, y también en los sentimientos de la gente. De otra manera no podríamos comprender con qué argumentos algunos defendieron sus derechos y no cedieron frente a las extorsiones de sus verdugos y cancerberos. ${ }^{3}$

Estos libros fueron escritos por intelectuales notables, algunos comprometidos con la impartición de justicia, y todos ellos imbuidos del deseo de buscar el bien común y la felicidad, convencidos de que estaban viviendo en una época de "fermentación general" en la que los príncipes, las corporaciones y los particulares se dedicaban con todo empeño a erigir por todas partes nuevos códigos que consideraban "monumentos ilustres a la humanidad, que harían eterna su memoria". ${ }^{4}$ Estos autores habían abrevado de las fuentes más adelantadas de su época. Referente ineludible era para ellos El espiritu de las Leyes del Barón de Montesquieu; pero muchos no eran ajenos a la tradición inglesa representada por los escritos de Howard, aquel benemérito que visitó más de 100 cárceles, y dejó constancia de la necesidad de un trato más humanitario hacia los delincuentes y de los peligros que podrían resultar de las miserias de la vida carcelaria. ${ }^{5}$ Podría objetarse que las tradiciones españolas

${ }_{3} \mathrm{Al}$ respecto pueden verse los procesos de Hidalgo y Morelos. En esa línea mi artículo IBarra, "Los castigos y los argumentos.

${ }^{4}$ Lardizábal y URibe, Discurso sobre las penas..., 1782.

${ }^{5}$ Howard, The State of Prisons. Este y otros trabajos de Howard pueden consultarse en The Library Company de Filadelfia (Penn), una de las bibliotecas más ricas de Estados Unidos en libros antiguos y que fue de gran utilidad para la elaboración de este trabajo. En todo el periodo la tradición inglesa será un importante referente para estos temas, muy destacadamente la obra de Jeremy Bentham, The Rationale of Punishment (1830). Sobre la importancia del utilitarismo puede verse CovarRubias, En busca del hombre útil. 
estaban cerradas por entero a estas posibilidades, sin embargo, la evidencia muestra que los intelectuales de la España ilustrada estaban en contacto con estos círculos, sin renegar por ello ni de su religión ni de sus tradiciones. Hay en todo esto más comunicación y mayor circulación de ideas de la que imaginamos.

Para entender esta interacción entre continuidad y cambio es necesario apreciar las polémicas de finales del siglo xviII desde una perspectiva más amplia. Un panorama internacional que obliga a ver las dos orillas del Atlántico. La larga historia de las ideas en torno a la justicia y los derechos humanos comienza mucho antes pero se afianza en el contexto de las reformas del Duque de Toscana, de María Teresa y otros monarcas europeos, con la aparición de las declaraciones de Virginia y en los círculos de beneficencia estadounidenses, contemporáneos a la revolución constitucional. ${ }^{6}$ La España ilustrada tiene que vérselas con los sectores recalcitrantes que obstaculizan de mil maneras el ímpetu reformista, pero éste consigue al menos publicar algunas obras que a pesar de las restricciones impuestas por la censura aparecen y llegan a los lectores por distintos caminos.

${ }_{6}^{6}$ Para la historiadora estadounidense Lynn Hunt, la Declaración de los Derechos del Hombre y del Ciudadano simboliza la promesa de derechos humanos universales. Consúltese Hunt, La invención de los derechos humanos. Otros autores que estudian el tema, como Samuel Moyn, consideran que la idea de los "derechos humanos" es algo más reciente y no aparece sino cuando se hace posible la internacionalización de los sistemas jurídicos; esto ocurre cuando algunos movimientos sociales de la década de 1970 levantan esta bandera. Moyn, The Last Utopia. Personalmente, no empleo las palabras "derechos humanos" para referirme a las discusiones de la época de las luces aunque, no cabe duda, es aquella la época en que nace la defensa de los derechos. 
Pero, ¿por qué dedicarle tanto espacio a estos escritos cuando la sociedad novohispana era víctima de la Inquisición y de muchos castigos arbitrarios, cuando el asunto de los derechos del hombre y de los acusados era algo tan lejano, al punto que todavía hoy sigue siendo un tema pendiente? Quiero poner un contrapeso a la amplia literatura que se ha ocupado de ello para darle una oportunidad a esta otra fuerza que constituye un impulso que como quiera que sea se abrió paso para formar parte de nuestras mejores tradiciones. Tradiciones que evocan el espíritu de unas luces que en términos generales se han visto como europeas, pero que encuentran un lugar en los documentos constitucionales de comienzos del siglo xix, y desde luego en intelectuales americanos como Mariano Beristáin, Jacobo de Villaurrutia, Agustín Fernández de San Salvador, Carlos María de Bustamante, Lucas Alamán y José Joaquín Fernández de Lizardi. De no revisarlos, una parte importante de esta historia queda en la penumbra.

\section{DOS OBRAS ENTRELAZADAS}

Entre la traducción al castellano de la obra Dei delitti e delle pene de Cesare Bonesana, Marqués de Beccaria ${ }^{7}$ (1774), y la publicación del Discurso sobre las penas de Manuel de Lardizábal y Uribe ${ }^{8}$ (1782) median ocho años. Ambas llegaron a las prensas españolas bajo el impulso de los ministros reformistas que deseaban establecer las bases para la regeneración y reforma de los códigos y legislaciones. Ellos

\footnotetext{
${ }^{7}$ Dei delitti e delle pene, Mónaco (Ligure), s. f. (1764).

${ }^{8}$ Discurso sobre las penas.
} 
estaban conscientes de que en el resto de Europa se vivía un fuerte debate en materia de justicia que había desembocado en temas fundamentales, como los alcances de la justicia del rey, la obligación del Estado de garantizar la seguridad, y la importancia de hacer proporcional al delito la administración del castigo. La preocupación por los asuntos penales llevó a Manuel de la Roda y otros a encomendarle a Lardizábal, un notable abogado nacido en la Nueva España y formado en la Península, la tarea de proyectar una reforma de las leyes del reino mediante la exploración cuidadosa de los códigos antiguos y su organización sistemática. ${ }^{9}$

Aunque la mayor parte de las reformas en materia judicial que planteó el programa carolino no se materializó en suficientes decretos, ni lo expresado se impuso con la contundencia que se esperaba, la existencia de varios de sus proyectos, sesiones, discusiones y trabajos dedicados a tales labores formó un sedimento sobre el cual se fueron tejiendo nuevas relaciones que hicieron posibles los cambios que trajo el siglo venidero. Ministros como el Conde de Aranda, presidente del Consejo de Castilla, el fiscal del Consejo, Pedro Rodríguez Campomanes, o el ya mencionado secretario de Gracia y Justicia, Manuel de la Roda, hicieron grandes contribuciones al tema, en ese periodo que algunos han denominado de incubación de cambios y de transformaciones. ${ }^{10}$ Como parte del programa carolino, se iniciaron

9 Sobre este proyecto penal y los ulteriores véase Tomás y Valiente, El derecho penal en la monarquía absoluta, pp. 263-267.

${ }^{10}$ Farriss se ha referido a éste como un periodo "de incubación de proyectos", pues todas estas ideas lograron concretarse a inicios del siglo XIX. Véase Farriss, Crown and Clergy in Colonial Mexico. Para los temas de justicia penal que nos ocupan, basta saber que entre 1808 y 1822 se 
también los trabajos para la elaboración del Nuevo Código de Leyes de Indias. ${ }^{11}$

Si bien cada uno de estos proyectos tuvo sus propios objetivos, es un hecho que estuvieron dirigidos por los mismos ministros que estaban colaborando en el diseño de las nuevas políticas, o por lo menos por los más comprometidos con la línea regalista de Carlos III. En conjunto, esas iniciativas tuvieron como propósito la redefinición de criterios para impulsar nuevas políticas en diversos temas específicos, como es el caso de la modernización de la justicia y la codificación.

El criollo tlaxcalteca Manuel de Lardizábal se integró a la junta especial encargada de revisar la Recopilación de Leyes de Indias, tarea de la que habría de resultar el primer libro del Nuevo Código de Leyes de Indias, que obtuvo la confirmación real en $1792 .{ }^{12}$

La publicación y aplicación de muchas de estas medidas sólo fue parcial y se optó por soluciones más conciliadoras y prudentes, ${ }^{13}$ lo que no quiere decir que las iniciativas

retomaron debates en torno a la cuestión que venían teniendo lugar desde 1770, y se hicieron serios avances sobre la materia. FARRIss, La Corona y el clero, pp. 219-228.

11 Sobre el proyecto del Nuevo Código de Leyes de Indias véase Muro Orejón, "Estudio general del Nuevo Código de Leyes de Indias", vol. II, pp. 3-87.

12 FARriss, La Corona y el clero, p. 103.

13 Farriss, La Corona y el clero, pp. 104 y ss. En 1806 se publica la Novísima recopilación de las leyes de España, durante el reinado de Carlos IV, que ya contaba con la sanción de la real cédula del 15 de julio de 1805 . El principal designado para su elaboración fue el licenciado Juan de la Reguera Valdelomar, quien fuera relator de la Cancillería de Granada, y que desde 1798 había sido comisionado para la revisión y preparación de este corpus. Por la serie de similitudes y defectos contenidos en la 
se abandonaran del todo. España tendría que esperar hasta las constituciones de Bayona y de Cádiz para ver plasmadas muchas de estas ideas, y hasta el trienio liberal para establecer un Código Penal, en 1822. ${ }^{14}$ Sin embargo, en estos años de transición crecía inevitablemente el interés por leer y traducir las obras que sobre estos temas se publicaban en otras partes de Europa. Lo que es más, fue en esas circunstancias que en el seno del grupo gobernante surgieron las iniciativas para buscar que estos trabajos salieran a la luz

Novísima, puede decirse que ésta no fue un código nuevo sino una reedición actualizada de la Recopilación, mismo punto que enfatizó Francisco Martínez Marina en su Juicio crítico de la novísima recopilación, de 1820. La Novísima... se compone de doce libros y también está dividida en varios títulos. En el libro XII de este corpus, De los delitos y sus penas, se prescribían los parámetros a partir de los cuales se debían valorar los delitos y las penas en todos los dominios hispánicos, incluyendo los de Indias. Entre los delitos mencionados están los hurtos, robos, homicidios, vagancia y otros varios.

${ }^{14}$ En aquellos años se consiguió la traducción y publicación de los distintos códigos penales y proyectos de códigos de los años 1820-1830. Véase por ejemplo el Código Penal del imperio francés, traducido a lengua española por el jurisconsulto Benito Redondo, México, reimpreso en la Oficina del Águila, 1825. Código Penal presentado por las Cortes de España en 8 de junio de 1822, y mandado observar por el Congreso Constitucional del Estado de Chibuahua en 11 de agosto de 1827, México, Imprenta de Galván, 1827, y Proyecto de Código Penal presentado al Cuarto Congreso Constitucional del Estado de Veracruz y mandado observar provisionalmente por decreto núm. 106 del 22 de abril de 1835, Jalapa, impreso por Aburto y Blanco 1835. La Constitución Bayona, texto en el que además de los agentes de Napoleón, participaron Manuel de Lardizábal y otros ministros por el Consejo de Castilla, fue el primer texto legal que suprimió la tortura en la Monarquía española. Dejando de lado su nula vigencia y efectividad en la práctica legal de la España invadida, su artículo 133 señalaba: "El tormento queda abolido; todo rigor o apremio que se emplee en el acto de la prisión o en la detención y ejecución y no esté expresamente autorizado por la ley, es un delito”. 
y se conocieran por el público. Tal y como lo ha apreciado Robert Darnton al estudiar fenómenos semejantes en la Francia prerrevolucionaria, los libros aparecidos bajo la censura del Antiguo Régimen responden a tendencias que el mismo Estado está interesado en impulsar, de tal forma que interviene en ello y ayuda a que se difundan, como sucedió entonces con toda la literatura de orden jurídico penal que se ha revisado para este ensayo. ${ }^{15}$

\section{LA FENOMENAL ACOGIDA DE LA OBRA DE BECCARIA}

Las ideas de Beccaria cundieron en muchos lugares como un reguero de pólvora mediante la publicación de una obra que pronto adquirió gran resonancia. Seguramente no pensaríamos que un escrito de esta naturaleza, referido a la impartición de justicia, la aplicación de castigos moderados, el final de la tortura y de la pena de muerte pudiera suscitar tan grande interés. Hablar de uno de los best sellers de su tiempo podría parecer exagerado, sin embargo, la lista de ediciones y traducciones de las que fue objeto nos hace recapacitar sobre ello.

Cesare Bonesana, Marqués de Beccaria, formaba parte de un grupo de jóvenes ilustrados que se reunía en la Accademia dei Pugni (Societá dei Pugni) de Milán. Seguramente las discusiones de este círculo de intelectuales lo impulsaron a sacar a la luz ese importante escrito que propuso poner fin a las formas de castigo corporal público que estaban vigentes

${ }_{15} \mathrm{Al}$ respecto puede verse el más reciente libro de DARnton, Censores trabajando, prácticamente dedicado a sostener esta tesis. Véanse en especial pp. 13-17 y 37-56. 
en la Europa de la primera mitad del siglo xvin. Casos sonados de la época, como el de Calas, defendido por Voltaire, por poner tan sólo un ejemplo, dieron lugar a que en muchos lugares surgiera una campaña que buscó la abolición de la tortura e incluso de la pena de muerte. La lucha a favor de los principios humanitarios y racionales que debían imperar en estos procesos se vio grandemente beneficiada por la aparición de una obra como Dei delitti e delle pene.

La edición original, de 1764, apareció sin fecha ni lugar de edición, pero es probable que se imprimiera en Mónaco (Ligure). No estaba dividida en parágrafos, como iba a ocurrir después, cuando apareció la segunda edición, en Livorno, en 1766, entonces sí dividida en 40 parágrafos e introducción. En esta segunda edición apareció la mentira de que había sido impresa en Harlem, e incluyó varias modificaciones que en ese par de años hizo el autor. Una tercera edición aparece en Lausana, con nuevos añadidos supuestamente en respuesta a algunas observaciones críticas del juicio de un célebre profesor. La sigue una más de Harlem (Livorno), en donde hay además un nuevo frontispicio. Hay una quinta, también de Harlem, y la siguiente, fechada en Buglione, que se cree impresa en Venecia, y a la que se añaden textos de otros autores (y que también aparece como sexta). ${ }^{16}$ Seguida de esta andanada de ediciones, a

${ }^{16}$ La información proviene de Notizie, que fue recogida en las obras completas de 1821, bajo el título de Opere di Cesare Beccaria. La edición de 1811 que, como se dijo había sido curada por Giuglio Beccaria, había estado precedida por esta amplia Notizie alla vita ed agli scritti del marchese Cesare Beccaria Bonesana, en la que se recuperan todas las ediciones de la obra localizadas hasta entonces. Hacia 1811, pero aún más para cuando se publican las obras completas, en 1821, Beccaria se habría con- 
petición universal sale a la luz una vez más la obra, en el año de 1767, ahora con el famoso comentario atribuido a Voltaire que acompañará en lo futuro muchas de las ediciones de la que fuera la obra más celebrada de Beccaria.

De acuerdo con la Notizie de la magnífica impresión hecha en Milán por Muzzi en 1811, cuya edición fue curada por el hijo del autor, Giuglio Beccaria, la versión en italiano de la obra se publicó también en Nápoles en 1770; Londres (¿Venecia?), en 1774: Harlem (¿París?, con el dato de que hasta esa fecha había habido diez ediciones), en 1780; hubo otras posteriores en París, Venecia, Milán, Bolzano, Pavía, Plasencia y Brescia, todas en italiano. A la fecha de la publicación de la hermosa edición muzzina, Dei delitti había sido objeto de 28 reediciones en italiano, es decir, 28 ediciones en poco más de 40 años. ${ }^{17}$ Por otra parte, el listado que ofrece indica que había sido traducida a siete idiomas: francés, alemán, inglés, holandés, español, ruso y griego vulgar $^{18}$-buena parte de estas traducciones habían sido hechas de la primera al francés, obra del abate Morellet-, dando un total de 23 traducciones que aparecieron en diversas capitales del mundo, lo que suma 52 ediciones en distintos idiomas, incluido el italiano original.

Todavía esta suma puede ampliarse si tomamos en cuenta lo que las imprentas del Nuevo Mundo sacaron a la luz

vertido ya en uno de los hombres de letras más exaltados en Italia. Con las obras completas recogidas en estos dos volúmenes, que incluyen Ricerca dello stile (Milán, Galeazzi, 1770), además del catálogo y las traducciones de la Bettoniana de 1807 y la Mussiana de 1811, queda constancia de que el autor es un consagrado de las letras italianas.

${ }_{17}$ Notizie.

${ }^{18}$ Notizie. 
en aquellos años, ediciones que no fueron contempladas en la relación de Giuglio Beccaria, que sólo consideró entre las estadounidenses la de Filadelfia de 1778. En realidad, la edición original de 1764 apareció muy pronto en inglés en Charlestown (Carolina del sur), 1777, publicada por David Bruce. Luego saldrían impresas Bell en Filadelfia las ediciones de 1778 y 1779; otra en italiano en 1780, en Nueva York, y una más en Filadelfia, en $1793 .{ }^{19}$ Nueva Inglaterra fue el taller responsable de la gran difusión de estas ideas en el continente, ya que ahí se imprimía y se traducía con gran eficacia. A los talleres de Filadelfia les debemos la edición de 1823 que circuló en el México recién independizado, pero seguramente desde antes hubo manera de tener alguna comunicación con lo que salía de las prensas de Filadelfia si consideramos que muchos exiliados vivían allá de imprimir y traducir obras al español. ${ }^{20}$

La primera traducción de Beccaría al castellano apareció diez años después de la edición original. Francia la había traducido inmediatamente (1766) y un año después se publicaba en Londres por Almon, con el comentario de Voltaire, el

19 Todas estas ediciones pueden consultarse en The Library Company, en la ciudad de Filadelfia. Agradezco al personal de esta fascinante biblioteca todas las facilidades brindadas para poder consultar gran parte de estos libros.

${ }^{20}$ Un buen ejemplo de ello es Santiago Felipe Puglia, quien se identificó como profesor de la lengua castellana y traductor, y trabajó para algunas casas editoras publicando obras en español. Una de sus traducciones es $E l$ derecho del hombre, para el uso y provecho del género humano, compuesto por don Thomas Paine, miembro de la Convención Nacional de Francia, secretario del Congreso durante la guerra de América, autor de la obra intitulada Common Sense, Filadelfia, Imprenta de Matías Carey e hijos, 1821. Por lo demás, la edición de 1823 puede consultarse en la Biblioteca Nacional de México, en adelante BNM. 
mismo año que la traducción alemana en Ulm. En 1768 se publicó en Amsterdam. Son mucho más tardías las traducciones al ruso, 1802, y al griego, 1803.

La edición española tiene su propia historia. ${ }^{21}$ Juan Antonio de las Casas fue el encargado de traducirla y se publicó bajo el sello del impresor Joachim de Ibarra en Madrid, el año de $1774 .{ }^{22}$ Aparece con 47 parágrafos e incluye la respuesta a las notas de la observación crítica del padre Facchinei. Se añadieron además algunas notas introductorias en las que se advertía al lector que lo allí expresado no buscaba ofender a quienes no estuvieran de acuerdo, sino exponer las ideas de un autor para ilustrar al público sobre un tema importante.

En realidad, la obra fue saludada en los círculos políticos más influyentes y figuras como Jovellanos, Alfonso María Acevedo, Manuel de la Roda y el propio Lardizábal vieron en ella un apoyo para hacer avanzar la reforma de las leyes penales y la elaboración de un código criminal. Sin embargo, recibió la oposición abierta de los sectores más reacios, que se vieron representados por publicaciones como la de Pedro de Castro, canónigo de la catedral de Sevilla, en su Defensa de la tortura, ${ }^{23}$ y la de fray Fernando de Ceballos, que fue el

${ }^{21}$ Muchos detalles respecto a la obra de Beccaria en España se los debemos a Antonio Delval, que pueden consultarse en la edición de BECCARIA, De los delitos y de las penas, pp. 177-190.

${ }^{22}$ Estos datos provienen de Notizia, contenida tanto en la edición de Muzzi de 1811 como en Opere di Cesare Beccaria, 2 vols., 1821, ya mencionadas. Como es posible advertir, hay en ese listado ediciones ausentes, como por ejemplo las que aparecieron en distintas ciudades de Estados Unidos, en donde floreció la actividad en torno a esta materia.

${ }^{23}$ Castro, Defensa de la tortura. La Academia de la Historia no autorizó su publicación; sin embargo, muy poco después, el Real Colegio de 
autor de un voluminoso trabajo titulado La falsa filosofía o el ateísmo, deísmo, materialismo y demás nuevas sectas convencidas de crimenes de Estado cometidos contra los soberanos y sus regalías, ${ }^{24}$ que se convirtió en una obra de referencia para las generaciones posteriores opuestas a la difusión del movimiento ilustrado. Ambas, y otras con mayor solidez argumentativa, incluyen pasajes críticos acusando a Beccaria de vulnerar los fundamentos de la Monarquía española. ${ }^{25}$ La Inquisición se apresuró entonces a condenarla, lo que dio lugar a una situación paradójica pues la obra ya había sido publicada pero ahora estaría prohibida. ${ }^{26}$

Una serie de reacciones diversas llevaron la discusión hasta 1785 , cuando el caso volvió a estudiarse. La intervención de figuras influyentes, como el Conde de Aranda hicieron

\footnotetext{
Abogados patrocinó su aparición añadiendo un comentario previo. Véase, Tomás y Valiente, El derecho penal, pp. 291-295. La obra puede consultarse en la BNM.

${ }^{24}$ Ceballos, La falsa filosofía o El ateísmo; o La falsa filosofía o El deísmo, en BNM.

${ }^{25}$ Por ejemplo, ese puede ser el libro de Muyart de Vouglans, y algunos otros del mismo género. Como se ha venido insistiendo, estas obras llegaron a la Nueva España y constituyen la fuente indirecta por medio de la cual se pudo tener noticia del libro de Beccaria. Muyart de Vouglans introduce en la segunda edición de su obra un capítulo a propósito de la obra de Beccaria y refiere con amplitud buena parte de la misma. Véase Muyart de Vouglans, Les loix criminelles de France.

${ }^{26}$ Cuando en 1774 apareció la obra de Beccaria en España, el clero la atacó inmediatamente y la Inquisición sacó un edicto en su contra el 30 de junio de 1777, prohibiendo su lectura a toda clase de personas. A juicio del inquisidor general, por una carta que dirigió al secretario de Gracia y Justicia, Manuel de la Roda, en mayo de 1777, el libro De los delitos y penas de Beccaria debía ser censurado debido a que estaban esparcidas en toda la obra innumerables proposiciones dignas de censura. Véase Tomás y VALIENTE, El derecho penal, pp. 257-263.
} 
posible que en la opinión hubiera más sensibilidad hacia el tema, de modo que se logró la autorización para que la obra transitara por lo menos en círculos restringidos. Entonces, a pesar de que la Inquisición la había condenado, la edición castellana pudo circular, lo que se añadía a la influencia de una obra que se conocía lo suficiente a través de las tantas ediciones y comentarios que había suscitado en otros lugares del mundo.

\section{ESPAÑA Y AMÉRICA EN EL CONTEXTO \\ DE LAS REFORMAS PENALES}

Este panorama adverso no impidió que las ideas igualitarias y las actitudes filantrópicas que se abrían paso en el mundo alcanzaran el espacio ibérico. Aspecto esencial que nutrió las transformaciones institucionales del siglo posterior, la discusión empezó a esbozar una ciencia de lo penal que décadas más tarde cobraría fuerza a través de academias, como la Academia de Ciencias Morales y Políticas en Francia, impulsada por Charles Lucas. ${ }^{27}$ Pensadores y hombres de acción abonaron en ese sentido, los escritos de Moreau de Saint Mery, La Rochefoucauld, Mathew Carey, William Cobbett y Benjamin Rush, y por supuesto las obras de Gaetano Filangieri, Jeremy Bentham, Benjamin Constant, Alexis de Tocqueville, que fueron muy conocidas en

${ }^{27}$ Charles Lucas fue un conocido abogado, inspector de prisiones y autor de varios libros y folletos. Entre otros, escribió Du systeme penal, 1827; Du systeme penitenciaire en Europe et aux Etats Unis, 1828; De la theorie, 1836; Projet d'étabblissement, 1832; y Discours devant la Societé de la morale, 1835. La posibilidad de consultar estos materiales se debe a la generosidad de The Library Company. 
América. ${ }^{28}$ A la mayoría de estos pensadores les parece que la razón y la humanidad tarde o temprano tendrán que imponerse y por ello invierten buena parte de su actividad en proyectos de muy diversa índole: de codificación, de inspección, de creación de proyectos y asociaciones.

La reacción de algunos de los jefes de Estado, todavía monarquías de Antiguo Régimen, los anima a mantenerse en esa expectativa pues la tortura es abolida en la segunda mitad del siglo xviı en Prusia, Toscana, Sajonia y Polonia. En 1756, se pone fin a la tortura en Ginebra, en 1768 en Rusia y en 1773 en Suecia. María Teresa y Luis XVI la suprimieron en Austria y Francia, en 1776 y 1780, respectivamente. De modo que son los déspotas ilustrados los que deciden tomar este rumbo pero sin abandonar sus propios derechos y prerrogativas, el principal, el de impartir justicia. ${ }^{29}$

Un folleto que circuló en francés a principios del siglo XIX se refiere con gran riqueza y profundidad a la utilidad y el derecho a imponer o no la pena de muerte a los condenados. ${ }^{30}$ En sociedades de Antiguo Régimen, la abolición de

${ }^{28}$ En otra línea resultan novedosos trabajos no exentos de la diatriba política de la época, como es el caso de Des prisons de Philadelphie de François de La Rochefoucauld-Liancourt (París, Chez Agasse, 1799); The Democratic Judge, de William Cobbett Filadelfia, 1798), o Revolutionary justice displayed or an inside view of the various prisons in Paris under the government of Robespierre and the Jacobins, taken from the journals for the prisoners themselves, traducido por M. Riouffe de la Convención Nacional, y proscrito por Robespierre Filadelfia impreso para Benjamin Davies por Richard Folwell, 1796), que pueden consultarse en The Library Company.

${ }^{29}$ Un espléndido desarrollo del tema en la obra de Clavero, El Orden de los poderes, pp. 72-116.

${ }^{30}$ Reflexions sur la peine de mort (panfleto), París, Imprimérie de Gille, s.f., se pregunta acerca de la utilidad de la pena de muerte y se plantea 
la pena de muerte -que es ya un tema muy avanzado- se basa en que, por encima de los debates de las asambleas, los monarcas ilustrados deciden hacer uso de su potestad para otorgar la conmutación de la pena de muerte en sus dominios. Es decisión y facultad suya, fruto de la "sabiduría real”, el que los condenados puedan tener la oportunidad de vivir para enmendar sus faltas. ${ }^{31}$

Es en particular interesante el caso de Pedro Leopoldo, real príncipe de Hungría Bohemia, Archiduque de Austria, gran Duque de Toscana, tan admirado por varios autores contemporáneos de Estados Unidos y de América Latina, ${ }^{32}$ que al acceder al trono planteó y llevó a cabo una reforma del sistema penal. Condujo tan lejos su intención de moderar los castigos que abolió la pena de muerte en Toscana, incluyendo cantidad de crímenes, aun el referido delito de lesa majestad. Pasó de la sentencia de conmutación a legislar en torno a la pena de muerte; eran iniciativas indudablemente radicales. ${ }^{33}$ Hay que decir, sin embargo, que ese mismo argumento, el de la sabiduría real y las determinaciones que podían derivar de ella, sirvió para que en otros lugares se decidiera revertir la medida. Así sucedió cuando Leopoldo de Bélgica, después de experimentar un incremento en la criminalidad, decidió, en 1832, restablecer la pena de muerte en sus reinos.

también el derecho que puede existir para terminar con la vida de otro hombre. En otro tenor muy distinto, Charles Lucas también aborda el asunto en Lucas, Sur l'abolition de la peine de mort en Belgique.

${ }^{31}$ LucAs, Sur l'abolition de la peine de mort en Belgique, pp. 14 y 15.

32 Alusivo a esa reforma penal, véase Extracts.

33 Extracts, pp. 14 y 15. 
Como se ha venido señalando, España no era ajena a estos movimientos. Algunos observadores contemporáneos comentaban desde el otro lado del Atlántico que, aunque los españoles no se habían animado a suprimir la tortura, era cada vez más claro que deseaban hacerlo y que la tortura era "vista con desaprobación". Les parecía que el hecho de que la apología de la tortura que había hecho el canónigo de Sevilla hubiera sido recibida con indignación ponía en evidencia la fuerte oposición que había hacia este tipo de ideas. Las dificultades que esa obra tuvo para alcanzar las prensas daban cuenta de la postura e influencia de los juristas que se habían inclinado en los últimos años en favor de la moderación de los castigos y las penas. ${ }^{34}$

En la asociación creada en Filadelfia para aliviar las penalidades de las prisiones públicas por grandes personajes como el científico y humanista Benjamin Rush, se comentaba lo siguiente:

En España se han hecho algunos avances bajo los auspicios del Conde de Aranda para estrechar la jurisdicción y humanizar el procedimiento de la Inquisición, y con tanto éxito que hace ya algunos años hubo bastante expectación pues parecía que había llegado el momento de que esta hidra que tanto habían condenado los filósofos al fin fuera destruida. ${ }^{35}$

Entonces, de acuerdo con la percepción que se tenía en otros lugares sobre la situación de la reforma penal en España, podemos decir que se entendía que había habido, en

\footnotetext{
${ }^{34}$ An enquiry, p. 50. Se refieren a la obra de Pedro de Ceballos, canónigo de Sevilla, cuya obra ningún editor serio quiso publicar en España.

${ }^{35}$ An enquiry, p. 51 y nota 1 de la p. 5.
} 
particular en 1783, como lo señalaban, esfuerzos muy valiosos para modificar las leyes criminales y algunos tribunales del reino. Pero que, desafortunadamente, diez años más tarde no estaba claro dónde habían desembocado tales esfuerzos. Ésta es la percepción que muestran folletos de la época que circulaban en otros lugares. ${ }^{36}$ ¿Es posible pensar que al aludir a estos esfuerzos los observadores externos estuvieran pensando también en la obra de Manuel de Lardizábal? No la mencionan expresamente, pero es indudable que en la percepción de lo que ocurría en aquellos años en España, estarían pensando en muchas de las iniciativas esperanzadoras que buscaban hacer cambios en materia de justicia penal.

EL DISCURSO SOBRE LAS PENAS Y SU APARICIÓN EN ESPAÑA

Después de lo acontecido en España con la obra de Beccaría, es presumible que el Discurso sobre las penas... planteara algunos asuntos con suma cautela. No tenemos evidencia de que el autor se lo hubiese propuesto, pero tampoco parece algo descabellado tomando en cuenta un contexto en el que algunos sectores se mostraban claramente adversos al espíritu de la Ilustración. Sea o no por esas razones, la obra de Lardizábal defendió la idea de que su obra expresaba las bondades de las más caras tradiciones españolas.

El Discurso sobre las penas contraído a las leyes criminales de España para facilitar su reforma fue publicado por

36 "El Consejo de Castilla lo propuso y se creó un comité para tal efecto, pero aún no se sabe qué ha resultado de ello...”, An enquiry. 
primera vez en Castilla en $1782 .{ }^{37} \mathrm{La}$ obra constituye una erudita disertación sobre las leyes, penas y prácticas criminales europeas, y principalmente sobre las aplicadas en la Monarquía. Tuvo como propósito dotar de mayores elementos al rey Carlos III para la regeneración y reforma de los códigos y legislaciones en esa materia, y sin duda se insertó dentro del concierto internacional de inquietudes y transformaciones que fue descrito en páginas anteriores.

La fuerza de la obra reside en su capacidad de introducir en España las ideas de moderación y humanización en el castigo, de proporcionalidad entre el delito y la pena, de separación entre las potestades temporales y espirituales. Su autor se manifiesta como partidario de la abolición de la tortura y de los castigos infamantes, no así de la supresión de la pena de muerte, que considera necesaria cuando la gravedad del crimen así lo amerite. A pesar de ser obra de un católico convencido, hombre de Antiguo Régimen, partidario de un orden corporativo, el Discurso sobre las penas... expresa su profundo compromiso con las luces de su época. Existe una confianza plena en la capacidad humana de regeneración y en la posibilidad de acceder a las luces mediante la educación. ${ }^{38}$

La obra representa un paso adelante en la difícil tarea de ir creando códigos unificados, tarea que no fue posible culminar en la España de la época pero a la cual hace un importante aporte. Lardizábal veía ese proceso como una "feliz revolución de los cuerpos de las leyes”, en la que nuevas

${ }^{37}$ Manuel de Lardizábal y Uribe, Discurso sobre las penas, 1782 . No hubo una segunda edición sino hasta 1828 , habiendo ya muerto su autor. 38 Para la discusión sobre la existencia de una Ilustración católica puede consultarse Chiaramonte, La Ilustración en el Río de la Plata. 
leyes, "acomodadas a las actuales circunstancias", irían reemplazando a las antiguas: "Las voluminosas compilaciones se reducen ahora a ordenanzas sencillas, claras y en poco número". Por eso encomiaba los resultados de las tareas que habían emprendido en sus vigilias muchos particulares, comprometiendo sus talentos y su instrucción para el "bien de la humanidad y felicidad de los pueblos". ${ }^{39}$

Como para la mayoría de los autores de su tiempo, para Lardizábal el punto de partida era el concepto de ley de Montesquieu, pero en cambio entabló discusiones abiertas con Rousseau y con Beccaria, por su "libertad inmoderada", como lo señala en varias ocasiones. Todo poder emana de Dios, en los términos de san Pablo, pues "no hay potestad que no venga de Dios”. Concebía además a la religión como un freno saludable para las sociedades. Dos cosas enteramente diversas y a considerar en toda legislación criminal eran el delito y el pecado, pues mientras que con el pecado se contravenía la ley divina interna o externamente, éste no perturbaba el orden y la tranquilidad pública del gobierno y los particulares, como sí ocurría con los actos externos de los delitos.

Un pensamiento impuro, por ejemplo, consentido interiormente con deliberación, es pecado, y pecado grave, pero no es un delito, ni está sujeto a las leyes humanas. Cualquiera mentira aunque leve, es pecado, y aunque sea grave, no es delito, si de ella no resulta perjuicio al bien público o a algún tercero. ${ }^{40}$

39 Lardizábal y Uribe, Discurso sobre las penas, 2005, pp. xxiii-xxiv.

40 Lardizábal y URibe, Discurso sobre las penas, p. 43. 
Pero el que Lardizábal se refiera a la potestad del monarca en materia de leyes, a que a él le pertenece la facultad suprema, la legislativa, porque el derecho de majestad dimana directamente de Dios, ${ }^{41}$ es un pensamiento que contrasta en definitiva con el de Rousseau y con el de Beccaria. El autor en consecuencia los refuta cuando defiende el orden estamental y el principio de que los castigos no pueden ser iguales para todos los individuos; de acuerdo con Lardizábal el noble que infrinja la ley debe ser castigado, pero no de la misma manera que un simple vasallo. Esta controversia deja muy en claro la postura del criollo americano y aleja la posibilidad de que pueda ser considerado discípulo de Beccaria.

Sólo tengo algunos elementos para precisar cuál fue el impacto de la obra en su momento, y me referiré a ellos un poco más adelante. Sin embargo, es necesario insistir en que habiendo sido publicada en 1782 no tuvo una segunda edición sino hasta el año de 1828, es decir, 40 años más tarde. La situación nos obliga a volver los ojos a la pérdida de ímpetu del proceso reformista en materia de justicia penal, el impacto en España de la situación política europea y las consecuencias de la muerte de Carlos III a finales de esa década. Los hermanos Lardizábal y otros de su grupo cercano padecieron el exilio motivado por sus diferencias con Godoy y, aunque mantuvieron una posición importante en círculos académicos prestigiados, dejaron de tener influencia en las decisiones políticas de la corona. Desterrados en la

${ }^{41}$ Para abundar en el complejo proceso de la modificación del poder judicial en esta época, véase el trabajo citado de Clavero, El Orden de los poderes, pp. 105-116. 
provincia española de Guipúzcoa, aunque ejerciendo labores intelectuales en la Real Sociedad Económica de Amigos del País de Vergara, permanecieron alejados de las decisiones políticas hasta que el motín de Aranjuez los devolvió a las filas de los partidarios de Fernando VII.

Algunos autores han hecho notar que el Discurso sobre las penas... desmereció frente a la influencia de la poderosa obra de Beccaria. Creo que esto es indudable. Toda una generación quedó eclipsada por esa obra que es punto de partida de las grandes discusiones en materia penal. No se deriva de ello sin embargo el que Lardizábal pueda considerarse un discípulo del célebre integrante de la Academia dei Pugni. ${ }^{42}$ El esfuerzo del jurista tlaxcalteca consigue reconciliar y salvaguardar los principales valores de la cultura española, una circunstancia que abre puntos de gran controversia con el autor de Dei delitti e delle pene y que le da una gran originalidad y fuerza propia al Discurso.

${ }^{42}$ No comparto la idea de ver a Lardizábal como discípulo de Beccaria en los términos en que lo establecen algunos autores. Para dar cuenta de esas posturas, un buen ejemplo es el trabajo de ONECA, "Historia del Código penal de 1822", pp. 264-265. Por lo demás, resulta lógico que el pensamiento de Lardizábal esté en el momento de la edición de su libro en la línea del pensamiento penalista del momento. También es comprensible que en 1822, cuando aparece el Código Penal en España, Bentham y Filangieri fueran más actuales que Lardizábal y que Beccaria, y éste fuera tan accesible y conocido, que carecía de sentido seguir a Lardizábal. La evolución de este proceso de producción de ideas en materia penal no resta interés ni importancia a la edición del Discurso sobre las penas, ni tampoco justifica que veamos a su autor como discípulo del otro. 


\section{UN INTERLOCUTOR PRIVILEGIADO}

En este conjunto de relaciones tan vasto entre las obras de la época, es menester resaltar la obra que fuera una de las más cercanas al Discurso. El diálogo que a lo largo de su vida sostuvo con su hermano, hace que no sorprenda el que uno de los primeros textos que recogen sus aportes sea precisamente la Apología por los agotes de Navarra, y los chuetas de Mallorca, con una breve digresión a los vaqueiros de Asturias, publicado por Miguel de Lardizábal en $1786 .{ }^{43}$ La voluminosa obra constituye una defensa de la igualdad natural del hombre, que no era lo mismo que la igualdad civil, así como de la tolerancia social y religiosa hacia los judíos y otros grupos afines con esas herencias culturales. Miguel era entonces miembro de la Real Academia Geográfico-Histórica de Valladolid. Como producto de la serie de discusiones que estaban teniendo lugar respecto a la renovación jurídico penal en la Europa del siglo XviII, es dable decir que este libro es una disertación en la que se perciben los ecos y el contacto del autor con las ideas que se estaban desarrollando y discutiendo en la Francia de Luis XVI. Resulta esencial también el debate entre "el orden natural” y el orden "civil de la monarquía”, así como las propuestas del jesuita francés Yves Marie André, el fraile español Luis de León, y particularmente de su hermano Manuel de Lardizábal. ${ }^{44}$

43 Lardizábal y URibe, Apología por los agotes de Navarra.

44 Sobre la relación entre las ideas de los dos hermanos puede verse Marín Tello, Delitos, pecados y castigos, pp. 121-161. 
Dejando de lado que muchos otros autores retroalimentaron la obra de Miguel, es importante mencionar que su trabajo tenía la finalidad de sentar las bases para terminar con el "injurioso ultraje y grandísima deshonra" que se cometía contra los agotes y chuetas por excluírseles de la sociedad como castigo motivado por sus orígenes heréticos. Su obra se oponía a la aplicación de penas infamantes de orden hereditario, pues explicaba que con su empleo, no sólo se atentaba contra estos dos grupos, sino contra la Naturaleza humana, la Justicia y el Derecho. ${ }^{45}$ Bajo el argumento del derecho e igualdad natural que debía existir en los hombres, el autor buscaba acabar con penas que ni si quiera habían sido producto de un delito y, al mismo tiempo, erradicar la "preocupación tirana" que persistía en contra de los agotes y chuetas, a quienes se infamaba y envilecía en "las más de las Provincias de España... [y principalmente en las capas bajas del] ínfimo pueblo de los necios". ${ }^{46} \mathrm{De}$ ese modo, además de constituir la defensa de grupos que injustamente habían sido marginados de hecho y de derecho por la propia corona y la sociedad, el Discurso también debe ser visto como la aportación de Miguel de Lardizábal a las reflexiones penales que estaban teniendo lugar en la Europa ilustrada de esos años, ${ }^{47}$ pero bajo la perspectiva de que

45 Marín Tello, Delitos, pecados y castigos, p. 60.

${ }^{46}$ Marín Tello, Delitos, pecados y castigos, pp. 2, 29 y 30.

${ }^{47}$ Como mencioné un poco más arriba, la difusión del juicio al padre de Calas en Toulouse durante 1761, dio lugar a que Voltaire publicara dos años más tarde su tratado a favor de la tolerancia religiosa, texto que además de reorientar a la opinión pública francesa contra los delitos religiosos y de infamia, contribuyó a generar un clima político y social para las reformas que tuvieron lugar algunos años después. Véase Voltaire, Tratado de la tolerancia, pp. 133-157. 
su Discurso discurría únicamente sobre este tipo de penas y su serie de negativas consecuencias en la sociedad, la justicia, la religión, y el gobierno.

Cuando se publicó en 1786 la Apología... de Miguel de Lardizábal, sólo habían transcurrido cuatro años desde que en 1782 saliera a la luz el Discurso sobre las penas... de su hermano Manuel. Producto de dicha circunstancia, en ambas obras se sostuvo una discusión crítica pero enriquecedora sobre la naturaleza de las penas y de los delitos. Para el primero, lo fundamental era contrarrestar la injusticia que se hacía en contra de la dignidad del hombre y su naturaleza por las penas infamatorias de orden hereditario y religioso. Para el segundo, lo más importante era la analogía que debía existir en toda pena con su delito, su razonable moderación, así como en la anulación de cualquier clase de castigo vinculado con la tortura y los suplicios.

Dicha discusión, empero, sólo puede ser aprehendida por la serie de citas, comentarios e interlocuciones que Miguel hizo al texto de su hermano en su propia obra, así como por la serie de referencias que se encuentra en su trabajo. Según se ha dicho, todo parece indicar que el primer interlocutor que tuvo el Discurso sobre las penas... de Manuel, fue el propio Miguel de Lardizábal en su Apología por los agotes... Dejando de lado el que las dos obras estuvieran dirigidas al monarca, los hermanos estaban convencidos de la desigualdad civil que debía existir en los gobiernos monárquicos y en general en cualquier clase de gobierno, pero también creían que el rostro de la justicia en España debía cambiar y sensibilizarse. Sin embargo, éstos no son los únicos temas en los que estuvieron de acuerdo. 
La medida y el alcance de los delitos, aspectos a los que me he referido en otros apartados, es lo que permitía distinguir entre distintos actos criminales. De hecho, todo acto delictivo debía partir de una intención razonada; sin ésta, cualquier sanción, además de ser inválida, debía ser considerada como injusta y arbitraria; ello sin importar la clase de gobierno, potestad, o príncipe del que se tratara. Desde la perspectiva de Miguel, ésta se definía como "la voluntad individual", o simple y llanamente como el "libre albedrio". Desde la perspectiva de Manuel, ésta se distinguía por las "intenciones de los actos" o la "moralidad humana", que debía estar presente en los delincuentes y sus acciones. ${ }^{48}$

En virtud de la definición y medida del delito, Manuel y Miguel compartían la percepción sobre el empleo anacrónico, arbitrario e injurioso que tanto la potestad pública como los particulares seguían haciendo de la infamia hereditaria que pesaba sobre individuos que eran inocentes. Por ello sugerían al monarca la inmediata proscripción del castigo por infamia, pues coincidían en afirmar que ésta era "una pena terrible" porque quien la padecía estaba expuesto a "perder el buen nombre, reputación [...] y toda consideración" de entre quienes le rodeaban. Era ésta una especie de "excomunión civil [que] rompe con todos los vínculos que le unían a sus conciudadanos [y dejaba] como aislado en medio de la sociedad" a quien la sufría. ${ }^{49}$ Los fines que debían perseguir tanto la aplicación de las penas como el Estado, también fueron temas en los que ambos hermanos

48 Al respecto, puede cotejarse Lardizábal y Uribe, Apología, pp. 80-81, con el Discurso sobre las penas, pp. 42-51.

49 Lardizábal y URibe, Apología, p. 64. 
encontraron puntos de unión en sus respectivos trabajos, y en los que hicieron notar la mala orientación de las políticas de la época en materia penal, así como lo incompatible de su actuar con respecto al resto de Europa. Siendo la pena el mal que uno debía padecer contra su voluntad, y siendo el Estado la autoridad que debía proteger la honra y bienes naturales de sus vasallos, señalan con toda justicia que: "a ninguno puede imponerse pena por delito que otro haya cometido", y principalmente, que era "un agravio, una injuria atroz $[. .$.$] y una pena injusta" si ésta era dictada por cual-$ quier institución del monarca. ${ }^{50}$

No obstante, y a pesar de la serie de avanzadas sugerencias que Miguel de Lardizábal dirigía al monarca y a su sistema penal, lejos se encontraba el novohispano de descartar el empleo de este castigo como medida para proteger a la sociedad de aquellos que por "un mal moral voluntario", o principalmente por "un mal físico trascendente", pudieran ponerla en peligro y serle perjudicial. En ese sentido, el autor creía que el empleo de los castigos de infamia sólo debía aplicarse a aquellos que incurrieran en el "envilecimiento de las costumbres" o cometieran cierta clase de "delitos de orden personal". Sólo en esas circunstancias, pensaba Miguel de Lardizábal, no quedaría violentado el derecho natural ni el de gentes, garantizando la dignidad que le era consustancial a todo hombre. De lo contrario, infamarle y privarle de la sociedad bajo argumentos de orden hereditario o religioso constituía:

50 Lardizábal y Uribe, Apología, pp. 64-65. 
[...] una injusticia notoria porque es no dejarle usar del derecho que le dan su naturaleza y su Autor: es una crueldad, porque es privarle de los mayores bienes, y esclavizarle a los mayores males, que proceden de la comunicación con los de su especie, y de la falta de ella: es una tiranía, porque es abusar de la fuerza para oprimir injustamente a quien no puede resistirla: es una degradación de la Naturaleza humana, porque es abatirla y condenarla en aquel hombre inocente al estado de soledad propio de las bestias, o de los delincuentes: y si se hace por desdén y menosprecio, es una degradación indecorosa, un ultraje injurioso, y una deshonra grandísima, porque es vilipendiar la Naturaleza humana despreciando su alta dignidad con injuria de su Autor. ${ }^{51}$

Si bien es cierto que tanto Manuel como Miguel coincidían en señalar que la pena de infamia no debía pasar de aquel que delinquía, lo cierto es que en este punto el pensamiento de ambos hermanos divergió por sendas propias. Mientras que Manuel consideraba que el uso poco frecuente y proporcionado de esta pena en la sociedad podía ser "útil para reprimir cierto género de delitos" que se fundaban en el orgullo y fanatismo (Manuel, pp. 87, 97-100), Miguel, por su parte, no veía con suficiente claridad los beneficios que podía atraer a la sociedad y al Estado el empleo de este castigo, y antes bien, consideraba que la aplicación de cualquier clase de pena de infamia por motivos religiosos era un tema que sólo podía ser juzgado por Dios, y no por los hombres y sus instituciones, quienes al arrogarse esa facultad estaban cometiendo un acto “antievangélico”, el cual era opuesto a la religión católica. ${ }^{52}$

51 Lardizábal y Uribe, Apología, p. 61.

${ }^{52}$ Lardizábal y Uribe, Apología, pp. 63 y 73. 
Como es posible apreciar, la discusión que promovieron los hermanos Lardizábal no era distinta de la que prevalecía en otros ambientes. Eran posturas avanzadas, que correspondían además con la labor que como jurista desempeñó Manuel en múltiples cargos durante ese periodo. Todavía los acontecimientos no se habían desbordado en la Península, como ocurriría con los cambios acelerados del periodo 1808-1823, cuando las transformaciones políticas y constitucionales hicieron fecundar las propuestas de aquellos años en torno a la falta de validez y de utilidad de los castigos infamantes, de la pena capital, del estado de las prisiones, la posibilidad de reflexión individual y la enmienda de los criminales. Todo ello traería como resultado un mundo muy distinto para el siglo xix. Ese mundo no sería comprensible sin la avanzada a veces cauta, contradictoria, de las iniciativas que impulsaron algunos personajes.

EPÍLOGO. LA RESONANCIA DEL

DISCURSO SOBRE LAS PENAS EN LA NUEVA ESPAÑA

Sabemos que la obra de Lardizábal se conoció y circuló en la Nueva España muy pronto. El libro estaba a la venta en México en la tienda de don Joseph de Jáuregui por lo menos en 1789, según lo registra un anuncio de la Gaceta de México, ${ }^{53}$ y que costaba 10 reales. Este dato ayuda a explicar lo que puede suponerse cuando nos encontramos

${ }^{53}$ Gaceta de México, 1789. En el mismo número se anuncia que también en la tienda de Jáuregui se encontraba a la venta el Recurso de la fuerza de Covarrubias. 
frente a múltiples citas y menciones que hicieron los autores novohispanos al referirse a ella en años posteriores.

Desde una perspectiva erudita, Mariano Beristáin y Souza apunta en su Biblioteca Hispano Americana que el Discurso sobre las penas es "aunque pequeño... como la uña”, suficiente para que a través suyo "la posteridad [conozca] la grandeza y nobleza de este León de la jurisprudencia española". ${ }^{54}$ Toda la bibliografía jurídica posterior habría de reconocerlo.

La trascendencia de la obra de Lardizábal alcanzó también los ambientes literarios y de la opinión pública, desde donde se puso al alcance de un público amplio, incluso popular, que la evocó como asidero en el cual confiar en una época en la que los acontecimientos corrían con un torbellino de novedades. Piénsese si no en el trabajo de Lizardi que tuvo muy presente al gran jurista, ${ }^{55}$ o en Agustín Pomposo Fernández de San Salvador y Jacobo de Villaurrutia, que estaban entre los principales abogados de la Nueva España. Quienes lidiaron con la justicia tanto a nivel litigioso como en los debates de la opinión pública, ${ }^{56}$ quienes llegaron a las

54 Beristáin y Souza, Biblioteca Hispano-Americana Septentrional, vol. II, pp. 133-135.

${ }^{55}$ En estas y en otras páginas, Lizardi se expresó en los términos del Discurso sobre las penas de Lardizábal, y coincidió abiertamente con él en que había que asegurar las antiguas tradiciones y el derecho castellano pues, de todas las que había en el mundo, nuestras leyes penales eran las menos malas. La preocupación de Lizardi por los asuntos de las cárceles, los castigos y el mundo de la delincuencia es constante, por lo que en varias ocasiones expresa su respeto y admiración por Lardizábal. Véase FERnÁNDEZ DE LiZARDI, El periquillo sarniento, pp. 168-169.

56 Villaurrutia, "Copia de una exposición”, vol. iI, pp. 511-515. FerNández de San Salvador, "Razón de los bienes que dejó D.a María Leona Vicario”, vol. v, pp. 172-174; Bustamante, Cuadro bistórico de la revolución mexicana, vols. I y IV, pp. 248-255 y 382-389. 
mazmorras y las cárceles, en más de una ocasión mencionaron a Lardizábal.

Cabe recordar como cierre de este ensayo, por la cercanía que guarda con los problemas tratados por el autor del Discurso sobre las penas, el pasaje en que Lizardi nos refiere el viaje del Periquillo al Oriente. Allí le toca al protagonista presenciar unos tremendos suplicios. Los jueces reunidos deliberando para ver si alguno de aquellos infelices era inocente, en tanto ellos eran cruelísimamente castigados: "unos empalados, otros ahorcados, otros más azotados y casi todos marcados en sus caras con fierros ardientes o con las manos derechas cortadas”. La obligada conversación de los viajeros los lleva después a reflexionar sobre la innecesaria crueldad de los castigos, la necesidad de hacerlos proporcionales al crimen cometido, en suma, la impartición de la debida justicia como garantía de la salud de la república, que es, como lo afirma el Periquillo, la suprema ley. Recordando a Lardizábal, Lizardi pone su confianza en los legisladores y concluye: "cada reino tiene sus leyes particulares y sus costumbres propias que no es fácil abolir, así como no lo es introducir otras nuevas”. Dejemos pues “a los legisladores el cuidado de enmendar las leyes defectuosas según las variaciones de los siglos $[\ldots]$ ”. ${ }^{57}$

\section{REFERENCIAS}

An enquiry

An enquiry how far the punishment of death is necessary in Pennsylvania, con notas e ilustraciones de William Bradford, Philadelphia, 1792.

57 Bustamante, Cuadro histórico de la revolución mexicana, vol. I, p. 72. 
Beccaria, Cesare Bonesana, marqués de

Tratado de los delitos y de las penas/Nueva traducción con el comentario de Voltaire, la respuesta de Beccaria a las notas y observaciones de Facchinei, las observaciones de Hautefort, las cartas relativas a la obra, las consideraciones de $M$ Roederer sobre la pena de muerte, las notas (entre las cuales algunas inéditas) de Diderot, de Morellet, de Brissot de Warville, de Mirbeau, de Servan, de Rizzi, de M. Berenguer, etc., Madrid, Albán, 1822.

Disertación sobre los delitos y penas, traducción al español, Filadelfia, 1823.

De los delitos y de las penas. Con el comentario de Voltaire, prólogo de Juan Antonio Delval, Madrid, Alianza Editorial, 2006.

Dei delitti e delle pene, Mónaco, Ligure, 1764.

Beristáin y Souza, Mariano

Biblioteca Hispano-Americana Septentrional, México, Tipografía del Colegio Católico, 1883, vol. II.

Bustamante, Carlos María de

Cuadro histórico de la revolución mexicana..., vols. I y IV, México, Imprenta de J. Mariano Lara, 1843.

Castro, Pedro de

Defensa de la tortura y leyes patrias que la establecieron e impugnación del tratado que escribió contra ella el doctor D. Alfonso María de Acevedo, Madrid, Miguel Escribano, 1778.

Ceballos, fray Fernando de

La falsa filosofía o El ateísmo, deísmo, materialismo y demás nuevas sectas convencidas de crimen de Estado contra los soberanos y sus regalias, contra los magistrados y potestades legitimas, Madrid, Antonio Sancha, 1774-1776.

La falsa filosofía o El deísmo refutado en todas sus hipótesis y convencido de crimen de estado, Lisboa, Oficina de Juan Procopio Correada Silva, 1800. 
Chiaramonte, José Carlos

La Ilustración en el Río de la Plata, Buenos Aires, Sudamericana, 2007.

Clavero, Bartolomé

El Orden de los poderes. Historias constituyentes de la trinidad constitucional, Madrid, Trotta, 2007.

Cовветт, William

The Democratic Judge, Phil., publicado por William Cobbett, frente Chirst Church, 1798.

Código Penal

Código Penal del imperio francés, traducido a lengua española por el jurisconsulto Benito Redondo, México, reimpreso en la Oficina del Águila, 1825.

Código Penal presentado

Código Penal presentado por las Cortes de España en 8 de junio de 1822, y mandado observar por el Congreso Constitucional del Estado de Chibuahua en 11 de agosto de 1827, México, Imprenta de Galván, 1827.

Covarrubias, José Enrique

En busca del hombre útil. Un estudio comparativo del utilitarismo neomercantilista en México y Europa (1748-1833), México, Universidad Nacional Autónoma de México, 2005.

DARnTON, Robert

Censores trabajando. De cómo los Estados dieron forma a la literatura, Estados Unidos, Fondo de Cultura Económica, 2014.

Extracts

Extracts and remarks on the subject of punishment and reformation on criminals, published and order of the Society established in Philadelphia for alleviating the miseries of public prisons, Philadelphia, printed by Paulson Jr., 1790. 
FARRISS, Nancy

Crown and Clergy in Colonial Mexico. 1579-1821: The Crisis of Ecclesiastical Privilege, Oxford, University of London, Athlone Press, 1968.

La Corona y el clero en el México colonial, 1579-1821. La crisis del privilegio eclesiástico, Estados Unidos, Fondo de Cultura Económica, 1995.

Fernández de Lizardi, José Joaquín

El periquillo sarniento, México, Librería de Galván, 1842, vol. II.

Fernández de San Salvador, Agustín Pomposo

"Razón de los bienes que dejó D.a María Leona Vicario en esta Casa número 19 de la calle de D.n Juan Manuel, donde habitaba en mi compañía, aunque teníamos separadas familias y habitaciones", en GARCía, 1910, vol. v.

García, Genaro

Alumnos distinguidos, México, Librería Bouret, 1908, vol. 21. Documentos históricos mexicanos, México, Museo Nacional de Arqueología, Historia y Etnología, 1910.

Ibarra, Ana Carolina

"Los castigos y los argumentos. El clero novohispano ante la revolución de independencia, en Schmidt, Dorsch y Herold-Schmidt (coords. y eds.), 2011.

Howard, John

The State of Prisons in England and Wales, Londres, 1784.

Hunt, Lynn

La invención de los derechos humanos, Madrid, Tusquets, 2009.

Jovellanos, Gaspar Melchor de

El delincuente honrado, Madrid, Viuda de Ibarra, Hijos y Compañía, 1787. 
Lardizábal y Uribe, Manuel de

Discurso sobre las penas contraído a las leyes criminales de España para facilitar su reforma, México, Porrúa, 2005.

Discurso sobre la legislación de los visigodos y formación de libro o Fuero de los jueces y su versión Castellana. Prologo al Fuero Juzgo, Madrid, Edición de la Real Academia de la Lengua-Imprenta Ibarra, 1815.

Discurso sobre las penas, contraído a las leyes criminales de España, para facilitar su reforma, Madrid, Imprenta de Ibarra, 1782. Segunda edición: Madrid, Imprenta de Repullés, 1828.

Apología por los agotes de Navarra, y los chuetas de Mallorca, con una breve digresión a los vaqueiros de Austrias, Madrid, Viuda de Ibarra, 1786.

Discurso sobre las penas contraído a las leyes criminales de España, para facilitar su reforma, Madrid, Joachin Ibarra, 1782.

La Rochefoucauld-Liancourt, François de

Des prisons de Philadelphie, París, Chez Agasse, 1799.

Lucas, Charles

Sur l'abolition de la peine de mort en Belgique, París, G. Pissin, Place du Palais de Justice, 1835.

Discours devant la Societé de la Morale, 1835.

De la theorie del emprissonement et des principes, moyens et conditions pratiues, 1836.

Du systeme penal et du systeme repressif général, de la peine de mort en particulier, 1827.

Du systeme penitenciaire en Europe et aux Etats Unis, 1828.

Projet d'étabblissement par suscriptions d'une maison de jeunes détenues, 1832.

Marín Tello, Isabel

Delitos, pecados y castigos. Justicia penal y orden social en Michoacán, 1750-1810, Morelia, Michoacán, Universidad Michoacana de San Nicolás de Hidalgo, 2008. 
Martínez Marina, Francisco

Ensayo histórico-crítico sobre la legislación y principales cuerpos legales de los reinos de León y Castilla, Madrid, Aguado, 1834.

Muyart de Vouglans, Pierre François

Les loix criminelles de France, dans leur ordre naturel, París, Merigot le jeune, Crapart, Benoit Morin, 1780.

Moyn, Samuel

The Last Utopia: Human Rights in History, Cambridge, The Belknap Press of Harvard University Press, 2012.

Muro Orejón, Antonio

“Estudio general del Nuevo Código de Leyes de Indias”, en Homenaje al Dr. Muro Orejón, Sevilla, Facultad de Filosofía y Letras, Universidad de Sevilla, 1979, 2 volúmenes.

Notizie

Notizie alla vita ed agli scritti del marchese Cesare Beccaria Bonesana, Milán, Muzzi, s.f.

Oneca, J. Antón

"Historia del Código penal de 1822", en Anuario de Derecho Penal y Ciencias Penales, t. 18, fasc./mes 2, 1965.

Opere

Opere di Cesare Beccaria, Milán, Muzzi, 1821, 2 volúmenes.

Paine, Tomás

El derecho del hombre para el uso y provecho del género humano, compuesto por don Thomas Paine, miembro de la Convención Nacional de Francia, secretario del Congreso durante la guerra de América, autor de la obra intitulada Common Sense, traducción de Santiago Felipe Puglia, Filadelfia, Imprenta de Matías Carey e Hijos, 1821.

Proyecto

Proyecto de Código Penal presentado al Cuarto Congreso Constitucional del Estado de Veracruz y mandado observar 
provisionalmente por decreto núm. 106 del 22 de abril de 1835, Jalapa, Impreso por Aburto y Blanco, 1835.

Reflexions

Reflexions sur la peine de mort, París, Imprimérie de Gille, s.f.

Revolutionary

Revolutionary justice displayed or an inside view of the various prisons in Paris under the government of Robespierre and the Jacobins, taken from the journals for the prisoners themselves, traducción de M. Riouffe, Filadelfia, impreso por Benjamin Davies by Richard Folwell, 1796.

Ricerca

Ricerca dello stylo, Milán, Galeazzi, 1770.

Schmidt, Peer, Sebastian Dorsch, Hedwig Herold-Schmidt (coords)

Religiosidad y clero en América Látina: la época de las Revoluciones Atlánticas, Koln, Alemania, Böhlau, Verlas, 2011.

Tomás y Valiente, Francisco

El derecho penal en la monarquía absoluta (siglos XVI, XVII y $X V I I I)$, en Obras completas, I, Madrid, Centro de Estudios Políticos y Constitucionales, 1997.

Villaurrutia, Jacobo de

"Copia de una exposición presentada por D. Jacobo de Villaurrutía al Virrey Lizana y Beaumont, en que se defiende del cargo de traidor al rey, y afecto a la independencia de México, de que lo acusó D. Juan López de Cancelada, 22 de enero de 1810”, en García, 1910, vol. II.

Voltaire

Tratado de la tolerancia, Buenos Aires, Losada, 2003.

Trattato sulla tolleranza, prefacio de Salvatore Veca, traducción y cuidado de edición de Lorenzo Bianchi, Milán, Feltrinelli, 2009. 